\title{
08 | Wagnerianos, flâneurs, hombres-masa. Los ambientes sinestésicos en la arquitectura fin-de-siècle _Eduardo Prieto
}

Las atmósferas sinestésicas son un producto de la modernidad. Sus primeras y acaso más sutiles manifestaciones se producen a finales del siglo XIX en París, la urbe moderna y caleidoscópica, poco antes transformada por el barón Haussmann, y cuyas avenidas y pasajes ofrecían una variedad de estímulos sensoriales que se filtraban en el sensorio de los flâneurs. La puesta en escena se desplegaba por calles abarrotadas de personas y mercancías que parecían animadas, como señalaría con precisión Baudelaire, por una suerte de "corriente eléctrica". Incesante y cotidiano, este espectáculo no era otro que el de la vida moderna aunque, como pronto advirtiera el propio Baudelaire, el hormigueante tráfago capitalista acababa llevando a una inevitable melancolía, un spleen que rechazaba la normalidad burguesa [1].

La modernidad genera, así, al dandi, esa especie de genio romántico capitidisminuido que, sin poseer cualidades extraordinarias, aspira a la excelencia heterodoxa o, al menos, a una excepcionalidad que solo puede ya buscar en lo distinto, en lo lejano. Por ello, la modernidad produce la querencia por lo primitivo y lo exótico, y también por los ambientes sinestésicos, esos paraísos artificiales en los que los dandis buscan la verdad que no hallan en la cotidianidad, pero que sabrán invocar por medios insospechados. Los ambientes del dandi podrán ser de tipo psicotrópico, como los descritos tempranamente por De Quincey, Baudelaire o Gautier a la manera de premoniciones psicodélicas, pero también de tipo arquitectónico, vinculados a veces al decadentismo más extremo y tan densos que, por decirlo así, se podían cortar con una navaja. Basta recordar los óleos de Gustave Moreau, con sus espacios herméticos e inextricablemente mitológicos en los que la luz no ilumina, sino que produce aún más oscuridad, o los interiores descritos por J. K. Huysmans en $\dot{A}$ rebours ( $A$ contrapelo), la novela cuyo protagonista, Des Esseintes, un aristocrático dandi, resulta ser un creador de atmósferas tan epatantes como al cabo inútiles [2]. Enclaustrado y enfermo de spleen, Des Esseintes experimenta consigo mismo, mezclando el tacto con la vista, la vista con el oído, el oído con el gusto, para construir sofisticadas puestas en escena cuyo propósito no es más que combatir el aburrimiento. Despliega excéntricas sinestesias por las distintas habitaciones de su mansión, convertidas en una suerte de parque temático personal con atracciones como el llamado "órgano de boca", un mueble-bar conformado por barriles dispuestos a modo de tubos de órgano y llenos de licores con los que el anfitrión y sus invitados creaban en sus fauces auténticas sinfonías de sabores. En realidad, los espacios y gadgets sinestésicos soñados por Huysmans eran el fruto más maduro y decadentista de la larga tradición francesa de instrumentos sinestésicos [3] que había comenzado con la musique oculaire de C. G. Guyot o el "clavecín ocular" (1720) del jesuita Louis-Bertrand Castel -un artilugio temperado en doce tonos, cada uno de los cuales podía modificarse con la luz en 12 grados, dando como resultado los 144 tonos propios de un órgano que recorre 12 octavas en la escala cromática ${ }^{1}$ - y continuado con la multitud de máquinas cromastésicas construidas después, hasta llegar al "teclado de colores" presuntamente científico, diseñado por el psicólogo Louis Favre, contemporáneo de Huysmans.

La moda de las máquinas y ambientes sinestésicos se debía, por tanto, a razones culturales o, en cierto sentido, contraculturales. Pero también a otras de índole científica, como el desarrollo de la psicología experimental, que a finales del siglo xIX se había enfocado en las cuestiones relacionadas con la percepción humana en general y con la "audición coloreada" (es decir, la cromastesia) en particular. Dos eran los principios de esta psicología: los nervios y las vibraciones. Explicar el funcionamiento de los nervios y dar cuenta de su papel en la experiencia estética fue el propósito de uno de los padres fundadores de la psicología, Gustav Theodor Fechner (1801-1887), heredero de la Naturphilosophie romántica y muy influyente tanto en los teóricos de la Einfühlung como en los arquitectos del Expresionismo alemán. A mediados del siglo XIX, Fechner postuló la tesis del paralelismo psico-fisiológico, es decir, la creencia en la correspondencia biunívoca entre los fenómenos fisiológicos y psíquicos. Influidos por Fechner, Paul Souriau (1852-1926) y, sobre todo, Charles Henry (1859-1926), compaginaron el estudio de la óptica, la química, la medicina y también de aquella parapsicología a la cual era tan aficionada la época, con el objetivo de desvelar las analogías entre los sonidos, los colores o los olores, y establecer ciertos patrones comunes, cuantificables en la escala de medidas de una estética que, no por sinestésica, se quería menos rigurosa ${ }^{2}$ [4]. Como tal estética dependía del efecto de las ondas acústicas o luminosas que, desde la atmósfera, llegaban al cuerpo humano después
Resumen pág 57 | Bibliografía pág 61

Eduardo Prieto es arquitecto (UPM, 2003) y licenciado en Filosofía (UNED, 2004). DEA en Estética y Teoría de las Artes, y en Filosofía Moral y Política (UNED, 2007), y DEA en Proyectos Arquitectónicos Avanzados (UPM, 2012), con estudios de posgrado en la Technische Schule Kaiserlautern (Alemania) y la UNL de Santa Fe (Argentina). Doctor Arquitecto por la ETSAM. Doctorado Internacional con mención de excelencia (UPM, 2014), con la tesis Máquinas o atmósferas: la estética de la energía en la arquitectura, 1750-2000. Actualmente imparte las asignaturas Historia de la Arquitectura y el Urbanismo e Historia del Arte y la Arquitectura en la ETSAM (UPM).

\section{Palabras clave}

Atmósfera, ambiente, sinestesia, modernidad, Gesamtkunstwerk 

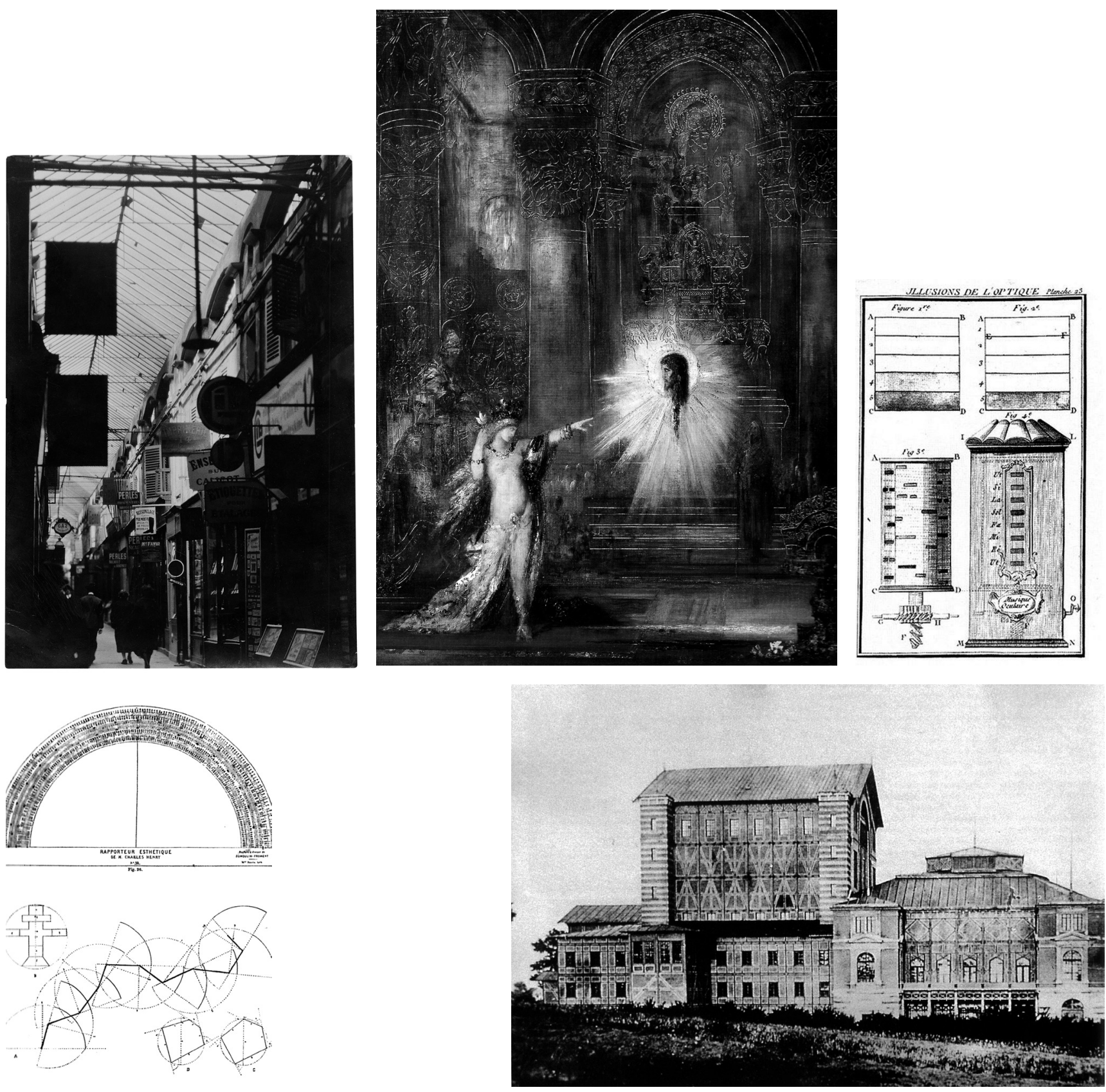

1 BLAS, Felisa de; Música, color y arquitectura, Nobuko, Buenos Aires, 2010, pp. 50-51.

2 Véase MARCHÁN, Simón; La estética en la cultura moderna, Alianza, Madrid, 2001.

${ }^{3}$ Véase HERNÁNDEZ, Sonsoles; Sinestesias. Arte, literatura y música en el París fin de siglo (1880-1900), Abada, Madrid, 2013, p. 95.

${ }^{4}$ SIMMEL, Georg; "La metrópolis y la vida mental", Bifurcaciones: revista de estudios culturales urbanos, $n^{\circ} 4,2005$ de atravesar los espacios habitados, pronto el énfasis se puso en la teoría de las vibraciones, que sería desarrollada por científicos como Eugène Veron (1825-1889) o artistas como Henri Rovel (1862-1926), para quien el hecho de que las siete notas de la escala musical se correspondiesen con los siete colores del espectro era una prueba de que el arte expresaba un orden universal de correspondencias vibratorias ${ }^{3}$.

Todas estas teorías se popularizaron hasta tal punto de que pronto se puso de moda la expresión irriter les nerviosités, que incluso Simmel incorporaría en su escrito sobre la metrópolis moderna al describir el efecto de shock que esta producía sobre el sistema nervioso 4 . Como había sentenciado por entonces el musicógrafo Albert Cozanet (1870-1938), vivir era en realidad vibrar, de ahí que la cuestión de cómo acentuar o atenuar el impacto de las vibraciones en el cuerpo se convirtiese en un asunto nada desdeñable. Partiendo de este contexto, hubo quienes concibieron el arte y la arquitectura como una herramienta para apaciguar el ánimo, para calmar la irritación nerviosa producida por las aristas o las formas desequilibradas -la mayoría de los filósofos de la Einfühlung-, y hubo quienes fueron más allá de esta simple función lenitiva para adjudicar al arte otros fines más ambiciosos cuyo objetivo, en último término, no era otro que conseguir la educación estética del hombre no ya a través de la Bildung schilleriana, sino de un proceso de moldeado material de los centros neurológicos.

La idea en que se basaba esta educación materialista del sensorio era que el cuerpo podía llegar a ser un resonador consciente de las ondas vibratorias que fluctuaban por el universo. 

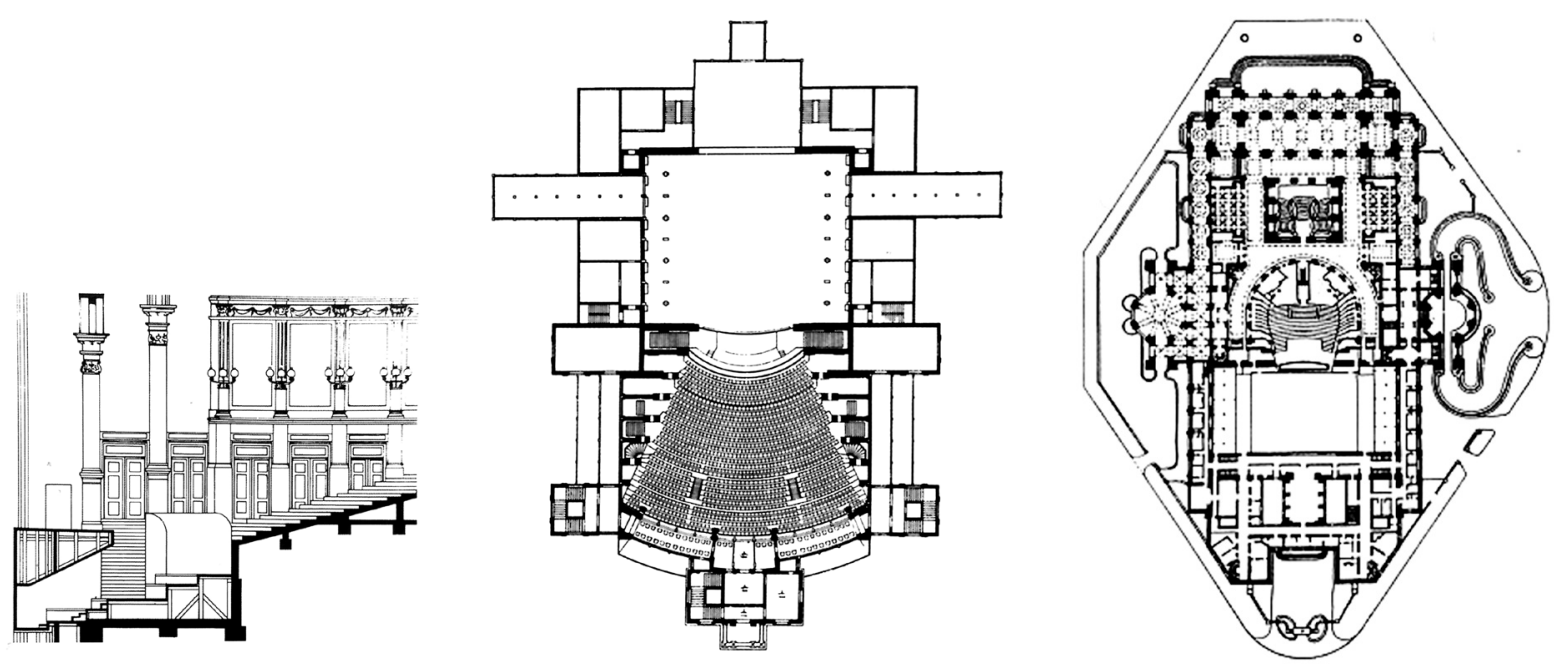

Para conseguirlo debía, empero, relacionarse con su ambiente inmediato de manera que este pudiera mediar adecuadamente entre el cosmos y la psique. Se trataba, en el fondo, de actualizar la vieja tesis del hombre como microcosmos a partir de una teoría psicofisiológica de las correspondencias según la cual, entre los fenómenos de la naturaleza y las percepciones del cuerpo humano, existía una relación biunívoca. Baudelaire había declarado en este sentido que el instinto de lo bello llevaba a "considerar a la tierra y sus espectáculos como un atisbo, como una correspondencia del cielo"; por ello, a través del arte el alma "atisbaba los esplendores situados detrás de la tumba", es decir, los principios invisibles del universo ${ }^{5}$. Correlato de esta correspondencia entre los sentidos humanos y la naturaleza era la que se producía entre las artes a través de la sinestesia, estableciendo relaciones de afinidad entre percepciones de diversa condición. El corolario era que unas artes podian considerarse como análogas de otras, pues las sensaciones experimentadas a través de un determinado sentido tenían su traducción en los estímulos de otro.

\section{De la psicología experimental a las Gesamtkunstwerke}

A la vez científica y esotérica, esta perspectiva resultó fundamental para refrendar una de las grandes hipótesis de la época: la de que las disciplinas artísticas debian colaborar unas con otras para producir una experiencia estética integral y potencialmente sinestésica, que pronto comenzó a denominare con el término que Wagner, inspirándose en los primeros románticos alemanes, había acuñado en 1849: la Gesamtkunstwerk, la "obra de arte total". Concebida por Wagner menos como una teoría de la pura sinestesia que como un principio de continuidad entre las artes -"allí donde una de aquellas artes alcanza límites infranqueables, empieza con la más rigurosa exactitud la esfera de la acción de la otra"6-, la obra de arte total pronto fue extendiéndose por la teoría artística contemporánea con unas connotaciones cada vez más extremadas, donde el énfasis se ponía, como en el caso ya citado de Baudelaire, en la capacidad del nuevo arte para producir una saturación sensorial semejante a la buscada en los paraísos artificiales, desbordando así, por la vía dionisiaca, los principios estéticos -belleza, racionalidad, armonía- propios del arte académico.

La más temprana y coherente materialización de la atmósfera densa de la Gesamtkunstwerk fue la escena del teatro proyectada por el propio Wagner en Bayreuth, cuya primera piedra se puso en 1872. Pese a que el proyecto tuvo el asesoramiento de Gottfried Semper -afamado especialista que había construido los teatros de Hamburgo, Dresde y Viena-, fue en realidad el resultado de un programa edilicio pensado y ajustado hasta el detalle por Wagner en función de sus ideales estéticos. La monumentalidad asociada al ornamento fue descartada de raíz. Al exterior, el edificio se presentaba como una esquemática carcasa desprovista de cualquier fasto $y$, en palabras de Wagner, "construida con el material más pobre". Era en el interior donde se producía el milagro, un espacio envolvente y mágico pensado como una suerte de reflejo intensificado de la vida que se desplegaba afuera, con su anomia cotidiana. Para producir el ensalmo, todos los recursos se orientaban no solo a segregar, como en otros teatros, el adentro del afuera, sino a reforzar también la separación ontológica entre la sala y el escenario, es decir, entre la avanzadilla de la normalidad burguesa y el espacio onírico donde se desenvolvería el arte depurado de cualquier funcionalidad, e inalcanzable.

Con este fin, Wagner manipuló la arquitectura de dos maneras: por un lado, duplicando el arco del proscenio para enmarcar con mayor énfasis la escena -dando lugar a la sensación

[6] El Mysticher Abgrund de la Festspielhaus de Bayreuth (Quesada, 2004).

[7] Planta de la Festspielhaus de Bayreuth (Quesada, 2004).

[8] Planta del Palais Garnier. LENIAUD, JeanMichel; Charles Garnier. Monum Éditions du Patrimoine, Paris, 2003.

[9] Sección longitudinal de la Ópera Garnier. LENIAUD, Jean-Michel; Charles Garnier. Monum Éditions du Patrimoine, Paris, 2003.

[10] El Palais Garnier el dia de su inauguración (1875). LENIAUD, Jean-Michel; Charles Garnier. Monum Éditions du Patrimoine, Paris, 2003. 

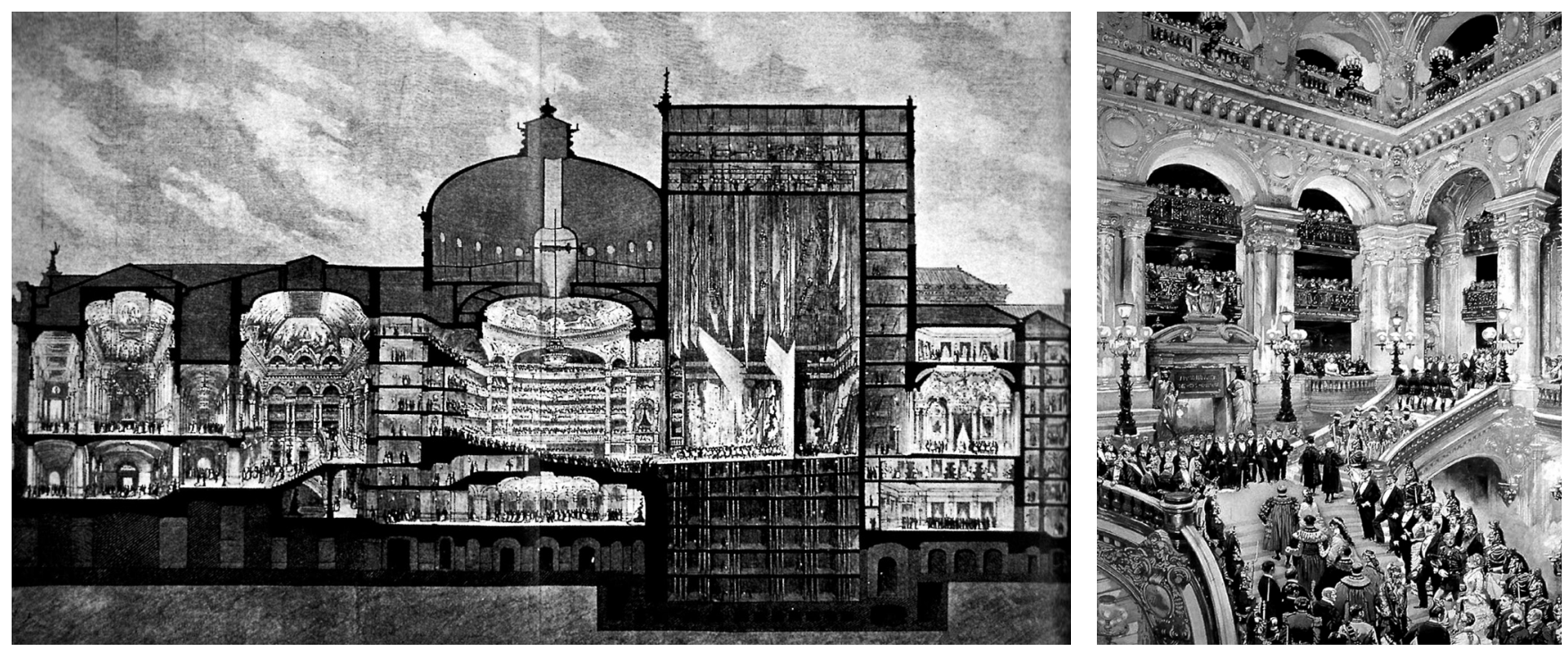

5 BAUDELAIRE, Charles; "Nuevos apuntes sobre Edgar Poe". En: Baudelaire, Charles; Poesía completa. Escritos autobiográficos. Los paraísos artificiales. Crítica artística, literaria y musical, Espasa Calpe, Madrid, 2000, p. 1.011.

${ }^{6}$ WAGNER, Richard; La obra de arte del futuro, Universitat de València. (Versión original: WAGNER, Richard; Das Kunstwerk der Zukunft, 1850, Verlag von Otto Wigand, Leipzig, 2000), p. 148.

${ }^{7}$ Citado en QUESADA, Fernando; La caja mágica. Cuerpo y escena, Fundación Caja de Arquitectos, Barcelona, 2004, p. 27.

${ }^{8}$ Fernando Quesada establece una pertinente contraposición entre el espacio escénico

barroco y el wagneriano: "La escena barroca confunde al espectador sobre la realidad $y$ la ilusión, pero el juego ilusorio termina precisamente en este punto, en el juego de los dobles, en el juego. En cambio, en Wagner, ambos planos están disociados, voluntariamente alejados uno de otro, al contrario de la escena barroca, en la que se funden. Wagner intenta elevar al espectador, hacerle reconocer un ideal y ofrecerle un camino para alcanzarlo, pero al mismo tiempo enfatiza la frontera que separa ambos ámbitos haciendo así consciente al espectador de la necesidad de un sacrificio realizado sobre sí mismo. La escena barroca envuelve al espectador en un torbellino sensual que lo agita sin una dirección determinada (...) mientras que Bayreuth establece una direccionalidad de la visión mucho más precisa y dirigida: detrás del abismo místico, únicamente." (Ibídem, pp. 29-30)

${ }^{9}$ Citado en VV.AA.; The Music of Colour: Natural Regeneration and Synaesthetic Architecture in Charles Garnier's Paris Opéra, 2010. óptica de que está más lejos-; por el otro, hundiendo el foso de la orquesta de manera que la atención se centrase exclusivamente en la representación, y que la música, concebida para sostener en todo momento dicha representación, pareciese provenir de algún lugar misterioso y remoto. Denominado por el propio Wagner como mysticher Abgrund (abismo místico), el foso tenía, en efecto, una condición que era telúrica y, por decirlo así, poliorcética: vinculaba el nacimiento de la música a las entrañas de la tierra a la vez que impedía el asedio del ojo, que nunca llegaba a conquistar la tramoya de la representación, manteniendo de este modo a raya al espectador estupefacto ${ }^{8}$. Era la música, al envolver a los oyentes, la que los transportaba como por ensalmo al otro lado del foso, produciendo un arrobamiento narcotizante; y era este, al cabo, el que los elevaba, cual si fueran comedores de opio, al mundo del estado catártico inducido por la exposición al arte [5-7].

Con su doble separación entre el interior y el exterior, y entre la sala y la escena, el teatro de Bayreuth inauguraba un tipo de disposición material de los ambientes o espacios atmosféricos que haría fortuna: aquella en la que una carcasa escueta y esquemática se combina con un interior denso y sofisticado. No se advierte tal en el edificio que, en muchos sentidos, puede considerase la némesis de Bayreuth: la Ópera de Charles Garnier, inaugurada en 1875, solo un año antes de que Wagner hiciese lo propio con su construcción. En el teatro parisino, la demarcación de la atmósfera no implica ningún esquematismo en la volumetría exterior. De hecho, el fasto decorativo es el mismo en las fachadas que en los espacios interiores. No se pierde en ningún momento la condición convencionalmente representativa de la arquitectura, sin que por ello resulte mermada la intensidad del ambiente habitado. La fluida y escenográfica transición que, desde la calle, conduce a la escena a través de un laberinto de escaleras y foyers propicia, en realidad, un doble juego teatral: por un lado, el de la ópera propiamente dicha; por otro, el de los cuerpos moviéndose por los espacios vestibulares para desempeñar el papel que les corresponde en la jerarquía social [9-10].

Con todo, la atención que Garnier, con una gran lucidez, prestaba a la atmósfera de la representatividad burguesa, no debilitaba la que concedía al juego escénico propiamente dicho. La verdad es que en este asunto el arquitecto se mostraba muy informado de los temas estéticos y de las investigaciones psicológicas que por entonces estaban en boga en Francia. Invocando la imaginería de los "espejismos orientales" que producen un "estupor narcótico", intentaba reproducirla en el auditorio, cuya ornamentación de colores brillantes estimulaba la vista y producía reacciones en los otros sentidos, envolviéndolos en una suerte de "suave perfume" que ponía a trabajar la imaginación de los oyentes para elevarlos hasta la dimensión del ideal artístico. La explicación que de todo ello daba el propio Garnier era más bien materialista: "Cuando los vapores exhalados por los pulmones de los espectadores, y los producidos por las luminarias, matizan los rayos de luz que los atraviesan, siendo imperceptiblemente agitados por las corrientes que los transportan, se da una suerte de vibración del aire que, unida al efecto de la brillantez dorada del ornamento, produce el efecto de un espejismo oriental. Primero queda seducido el ojo y, tras él, es la imaginación la que le sigue en una especie de sueño, y uno se siente entonces invadido por un sentimiento de bienestar." ${ }^{9} \mathrm{De}$ toda esta sutil performance resultaba una sensación de confort estético cuya base fisiológica era, como explicitaba Garnier, el fenómeno de la sinestesia: "La música de los sonidos es ciertamente grande y poderosa, pero también la música de los colores tiene su fuerza y su persistencia; es la música del color la que casi sin darnos cuenta modifica nuestros pensamientos y nuestras acciones: es el color rojo, el blanco, 

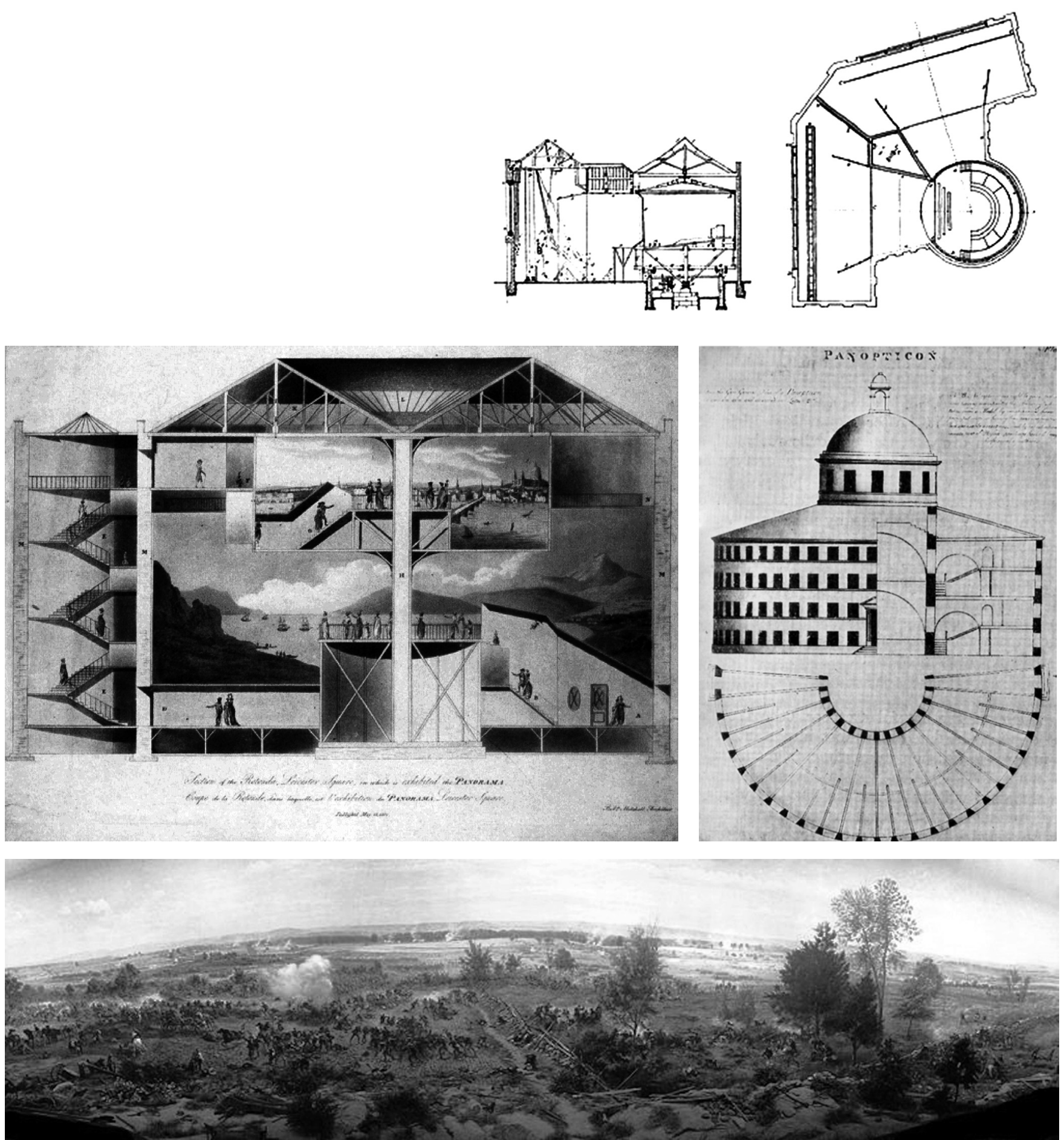

el azul, el negro o el verde el que, cuando domina nuestra atención durante un buen tiempo, vuelve a la imaginación y al corazón alegres o tristes, activos o melancólicos." ${ }^{10}$

Pero, por mucho que produjesen arquitecturas de atmósferas singulares, ni la Wirkung wagneriana ni el effet garnieriano podían considerarse, en puridad, como el resultado de un arte sinestésico literal. De hecho, el intento de construir obras multisensoriales se acabaría llevando a cabo por otro medio más sofisticado y paroxístico: el de las puestas en escena simbolistas del llamado Théâtre d'Art. Orquestadas bajo el liderazgo de Paul Napoléon Roinard (1856-1930) -un artista en el que se conjugaban la efervescencia esotérica con el conocimiento minucioso de las teorías sobre la audition colorée de Charles Henry-, las representaciones tuvieron lugar en París entre 1890 y 1892 . Aunque en ellas era posible advertir muchas de las ideas de su época, desde la teoría baudelairiana de las correspondencias artísticas - "los perfumes, los colores, los sonidos se responden"- hasta la noción del "arabesco como momento atmosférico" postulada por Debussy, pasando por la tesis de la equivalencia psicofisiológica de Fechner, Souriau o Rovel, las representaciones del Théàtre d'Art se des-

[11] Patente del panorama de Robert Barker (1787). Internet.

[12] El panorama de Leicester Square, Londres (ca. 1783). Internet.

[13] El Panopticon de Jeremy Bentham (1787). Internet.

[14] Panorama de la batalla de Gettysburg (1868), de Paul Philippoteaux. Internet.

[15] Affiche del Panorama de Gettysburg. Internet.

[16] Panorama de La batalla de Paris (ca. 1880), por H. F. E. Philippoteaux. Internet. 
10 Ibidem.

${ }^{11}$ HERNÁNDEZ, S.; op. cit., p. 257.

12 Mientras preparan juntos el guión de $\mathrm{La}$ Edad de Oro, Dali le escribe a Buñuel: "Pienso mucho en el cine táctil. Sería fácil y cojonudo si lo pudiéramos aplicar en nuestro film como simple ilustración. Los espectadores apoyan las manos sobre una tabla, en la cual sincrónicamente aparecen materias distintas: un personaje acaricia una piel, en la tabla pasa con piel, etcétera. Sería de efectos totalmente surrealistas y escalofriantes. iUn personaje toca un muerto y en la tabla los dedos se untan de masilla! Si pudiéramos con seis o siete sincronizaciones táctiles bien escogidas. Hay por lo menos que pensar eso para otra vez: el público se tiraría de cabeza" (citado en GIBSON, lan; La vida desaforada de Salvador Dali, Anagrama, Madrid, 2004, p. 327). vinculaban de los precedentes wagnerianos por su búsqueda mucho más explícita del ideal de autonomía artística. No se trataba ya de hacer de la escena otra realidad idealizada, sino de crear un espacio construido con sus propias normas, exclusivamente artístico, y en el que, además, el público participase poniendo en juego todo su sensorio. La audiencia se vería inmersa en esta atmósfera pura de ficción a través de una nueva manera de percibir que abría un paréntesis en la consuetudinaria y burguesa. Tal fue la función de las tramoyas diseñadas por Roinard para construir estos ambientes de ensueño, escenas formadas por una superposición de teloncillos de gasas en los cuales se pintaban motivos bíblicos o mitológicos, y cuya buscada translucidez producía la sensación de que se estaba ante una especie de vidriera onírica. Entre sus capas pululaban los actores ataviados con no menos vaporosos ropajes, que declamaban al modo simbolista con una artificialidad que confirmaba al cabo que la intención de todo el montaje no era desarrollar un argumento, sino sugerir estados de ánimo a través de distintos ambientes. Con todo, lo más singular del planteamiento no eran ni los telones ni la interpretación, sino la "orquestación" sinestésica que acompañaba a cada momento simbólico. Situados en los palcos superiores de la sala, poetas y técnicos de escena vaporizaban perfumes que seguían a la música de acuerdo a las tesis asociacionistas de la nueva ciencia de la "odoroscopia", que vinculaba, por ejemplo, la nota "re" con el perfume de violeta, la "mi" con el de acacia, el "fa" con el del nardo, el "sol" con el azahar, el "la" con el del heno fresco, el "si" con el de la aurora y el "do" con el del alcanfor ${ }^{11}$. Invisibles pero poderosos, los perfumes se dispersaban por toda la sala, contribuyendo a romper la separación mística entre escena y auditorio, y produciendo una sensación envolvente y multisensorial que, durante el tiempo que duraba la puesta en escena, alejaba a los espectadores de su anémica y unidimensional cotidianidad.

Aunque el Théâtre d'Art constituyó a la postre un fracaso, fue una de las primeras y más ambiciosas experiencias de representación sinestésica. La tradición que, comenzando con los fumoirs baudelairianos y las Gesamtkunstwerke wagnerianas, continuó con la arquitectura multisensorial de Garnier hasta desembocar en las tramoyas oníricas de Roinard, sería pronto retomada por parte de las vanguardias de principios del siglo xx, corrientes, sin embargo, menos ambiciosas que, influidas por la moda de la audition colorée, orientarían sus investigaciones exclusivamente a la equivalencia estética entre el color y la música. Kandinsky con su Der gelbe Klang (1911) -una puesta en escena basada en la correlación entre la sonoridad musical, la psíquica y la cromática-, Schönberg con su Die Glückliche Hand (1913) -una representación en la que la música se fundía con una dramática tramoya lumínica-, Scriabin con su Prometeo (1910) -una sinfonía "ilustrada" con un cromatismo paralelo a la música-, o incluso Dalí y Buñuel con su utopía de un cine táctil ${ }^{12}$, son ejemplos de propuestas artísticas sinestésicas que, con todo, palidecen frente las verdaderas "obras de arte total" que a lo largo de ese mismo siglo produciría la arquitectura más lúdica y menos engreída: la de la cultura de masas.

\section{Del panorama al ludotopo: sinestesias para las masas}

Desde luego, no eran "masas" las que habían asistido a la representación sinestésica del Théatre d'Art parisino, sino élites burguesas y sofisticadas a las que el espectáculo les había defraudado no tanto por su ambición desmedida cuanto por su falta de ritmo y su incompetencia técnica. Como la comparaban con las funciones ilusionistas y tremendamente convincentes de las muchas variantes de los panoramas entonces a la moda, la sensación no podía ser sino la de haber asistido a una obra de aficionados, cuando no a un simple timo. De hecho, los panoramas eran a finales del siglo XIX artificios tecnológicamente depurados y con solera. Habían sido inventados en 1787 por el pintor de retratos y miniaturas irlandés Robert Barker (1739-1806), con una pa-
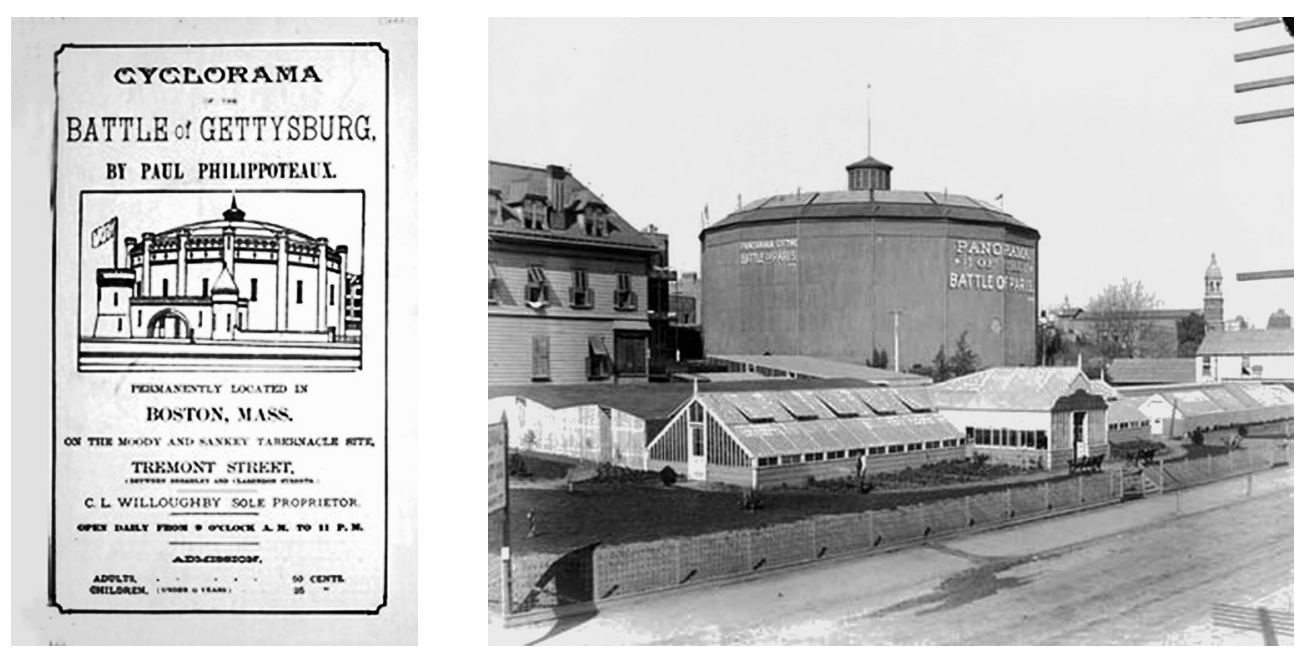

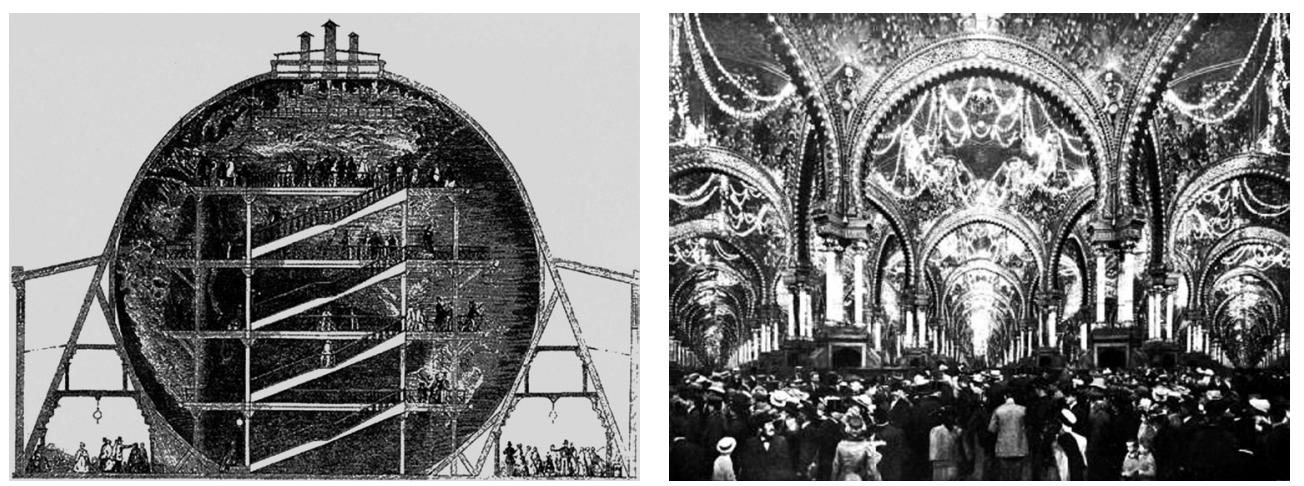

tente a la que bautizó La nature à coup d'oeil (la naturaleza de un vistazo), que consistía en una pintura cilíndrica y un edificio circular construido para mostrarla; en el centro se situaba una plataforma de observación cuyo encuadre hacía invisibles los límites superior e inferior de la pintura. El efecto era sorprendente, y el éxito de Barker fue inmediato. Construido un año después y casi a la par que el Panopticon de Jeremy Bentham -otro mecanismo de control óptico que tendría una larga descendencia-, el panorama de Edimburgo tuvo su sucesor en el de Londres. A ambos siguió el primer artefacto permanente de su especie: el panorama de Leicester Square (17931863), formado por una gran rotonda cuya piel exterior, esquemática, por no decir que anodina, protegía de la cotidianidad al mundo interior de ilusionismo desbordante, manteniéndolo en una suerte de ensalmo. El modelo de Barker sería pronto repetido con tanto descaro como profusión, y exportado fuera de Inglaterra: primero a Francia, donde John Vanderlyn pintaría entre 1816 y 1819 el célebre panorama de los jardines de Versalles que hoy se expone en el MoMA, modelo al que seguirían los no menos célebres artificios de Daguerre; más tarde a EE UU, cuando Paul Philippteaux presentó en Los Ángeles y Boston un inmenso panorama (1868) con varias escenas que recorrían con escalofriante realismo los sucesos de la batalla de Gettysburg [11-16].

Fue en Francia, sin embargo, donde la panoramanía alcanzó sus mayores cotas de paroxismo al calor de las innumerables exposiciones universales que albergó París entre 1850 y 1900. A diferencia de los espectáculos elitistas de la bohemia, los panoramas llegaban con facilidad al público general: generaban una fácil atmósfera envolvente que sugería al espectador una grata sensación de verdad o, por decirlo con términos actuales, de "realidad aumentada", tan feliz como falaz, pero que al cabo lo sacaba de su aburrimiento cotidiano. Con sus músicas, sus fuegos de artificio, sus fuentes luminosas y su profusión extraordinaria de objetos traídos de todo el mundo, las exposiciones universales se convirtieron en el mejor escenario para los panoramas y toda su larga descendencia, desde los dioramas a los mareoramas, pasando por los cosmoramas, noctoramas, udoramas, cicloramas, pleoramas o kineoramas, espectáculos que, a través de una mezcla sinestésica de sensaciones visuales, olfativas y acústicas, desplazaban al espectador de su estado de normalidad perceptiva para conducirle a otras realidades que no podría conocer en el mundo real si no fuese a través del artificio: una travesía en barco por el mar Mediterráneo, un paseo en globo, una excursión a una caliginosa caverna, un periplo en el Transiberiano o incluso un viaje estelar. El apogeo de las representaciones multisensoriales cristalizó en un singular edificio, el Museo Grevin de París, creado en 1882 para mostrar dioramas con muñecos de cera, por los cuales podían pasearse los visitantes, convertidos así en los auténticos protagonistas de un espectáculo cuyo efecto ilusionista se sostenía en sofisticadas tramoyas.

A las estrategias ilusionistas convencionales en el panorama pronto se sumaron las procedentes del rápido desarrollo tecnológico al que asistía la época, como la generalización del uso de la electricidad. Fue precisamente esta fuente de energía la que sostenía el efecto sinestésico de un edificio tan sensacional como el parisino Palais des Illusions, de 1900, anticipo de los muy posteriores espectáculos de luz y sonido. En otros casos lo buscado no era tanto la espectacularidad momentánea y epatante como la producción de una realidad total invocada fundamental-

[17] Great Globe: georama de J. Wyld (1851). Fuente: Internet.

[18] El Palais des Illusions de París (1900). PEVSNER, Nicolaus; Historia de las tipologías arquitectónicas, Gustavo Gili, Barcelona, 1979.

[19] El "baño eléctrico" de Lunapark (ca. 1900). Fuente: (Koolhaas, 2005). [20] El panorama de "La creación" en Lunapark. Fuente: (Koolhaas, 2005). [21] El panorama de "La caída de Pompeya" en Lunapark. Fuente: (Koolhaas, 2005).

[22] Lunapark, ca. 1900. Fuente: (Koolhaas, 2005).
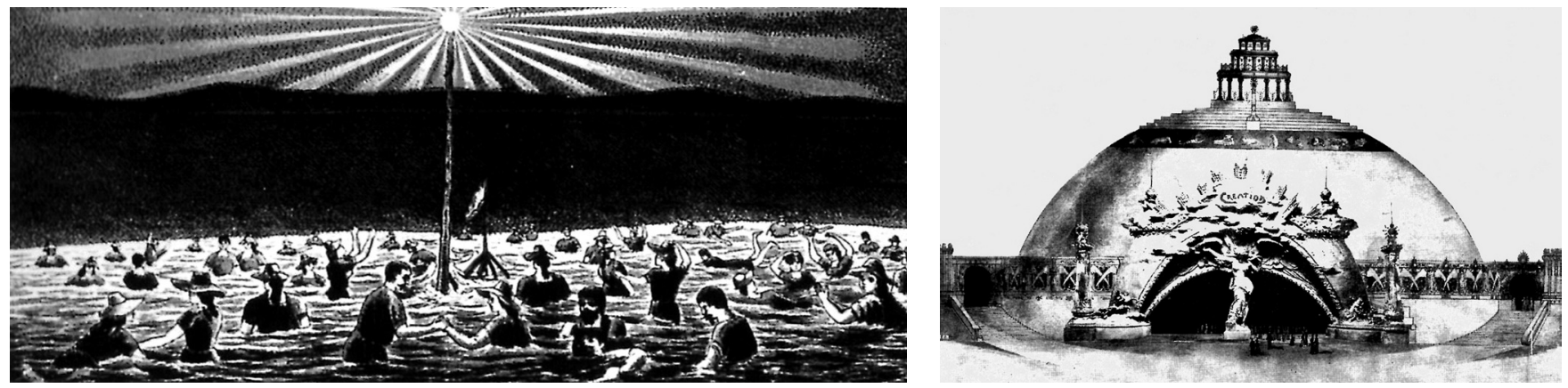
mente mediante mecanismos ópticos. El modelo de estas instalaciones fue, sin duda, el llamado "Gran Globo de Mr. Byld", presentado con ocasión de la Exposición Universal londinense de 1851 y que, como no pudo instalarse en el Crystal Palace, encontró acomodo en Leicester Square, no lejos del ya añejo panorama de Barker. Consistía en una enorme esfera aparejada con pasadizos y trampantojos, en cuyo interior se movía el público que contemplaba asombrado una sucesión de cuadros del globo terrestre. Obviamente, la lógica que asistía tanto al Globo de Mr. Byld como al resto de grandes panoramas y dioramas era construir una obra de arte total, envolvente y dirigida a todos los sentidos, evocando acaso la Gesamtkunstwerk de Wagner en una suerte de versión apta para todos los públicos [17-18].

Pero el paroxismo ilusionista y ambiental de la exultante Francia de la segunda mitad del siglo XIX se habría de quedar corto respecto a los grandes espectáculos que pronto se pergeñarían al otro lado del Atlántico. Allí el influjo de las exposiciones universales francesas y el insoslayable reto que suponía para los norteamericanos superar el evento londinense de 1851 -en particular, su Crystal Palace-, fueron en parte alicientes para construir la Exposición Colombina de Chicago en 1893, y en paralelo la más grande y vesánica instalación lúdica que hasta entonces se había presentado a las masas burguesas: el complejo Luna Park, situado en Coney Island, frente a Nueva York.

Este se empezó a levantar a partir de 1865, una vez que llegaron a la isla las vías del ferrocarril. A partir de entonces, y partiendo de la nada, aquella Las Vegas ante litteram comenzó a expandirse como un gas, hinchando una burbuja festiva que solo explotó cuando en 1911 todo aquel tinglado levantado por el ilusionismo capitalista se quemó, en una especie de crash estético. Luna Park constaba de espectáculos e instalaciones que en verdad dejaban atrás el Palais des Illusions, al Globo de Mr Byld o al Museo Grevin. Su tamaño era descomunal; su apariencia, exótica y fantasmagórica. Eran dioramas nunca antes tan inmensos ni veraces que reflejaban diversas épocas históricas: allí uno podía asistir a la Caída de Pompeya y ver cómo sus edificios y sus habitantes quedaban engullidos por la lava del atronador Vesubio; pasearse en góndola por los canales de Venecia; viajar a Liliputlandia, o disfrutar de una experiencia aún más remota y espectacular, como la que se daba en la llamada Cúpula azul -la "cúpula más grande del mundo"-, cuyo show daba cuenta nada más y menos que de toda la historia del universo, comenzando por la Creación hasta acabar con el Fin del Mundo en la versión del "sueño de Dante", según advertía el programa ${ }^{13}$.

${ }^{13}$ Citado en KOOLHAAS, Rem; Delirio de Nue va York, Gustavo Gili, Barcelona, 2005, p. 51.

En Luna Park, las instalaciones mecánicas más modernas tergiversaban las potencias del cuerpo, pero también cubrían sus limitaciones, ampliaban sus capacidades o superaban, al menos por un tiempo, sus prejuicios o escrúpulos. Tal era el caso de los "Barriles de Amor", dos cilindros horizontales que giraban lentamente en direcciones opuestas de manera que, alimentado el uno con hombres y el otro con mujeres, estos acababan promiscuamente mezclados, dando pie a una forzada intimidad, tan sintética como efímera. Además, para quienes nunca hubieran montado a caballo se ofrecía una atracción especial, la "Carrera de Obstáculos", formada por veloces potros mecanizados. Por su parte, los llamados "Baños eléctricos" proponían una inesperada manipulación de la naturaleza: potentes proyectores hacían posible un segundo turno de inmersiones nocturnas en el mar, ofreciendo así a los que no podían bañarse durante el día una ampliación artificial de 12 horas, y además una experiencia corporal y atmosférica completamente inédita que recuerda, considerándola con perspectiva, a muchas presuntuosas performances posteriores [19-21].

Por más que en su momento estas atracciones resultasen chocantes, en realidad su mayor singularidad fue el modo de expresar, digamos que "estilísticamente", su contenido interno y ambientalmente festivo. Lejos de manifestarse al exterior con comedimiento -como en los panoramas de Barker o Philippteaux-, el aspecto de los ludotopos norteamericanos era una verdadera prolongación del espectáculo que se daba en el interior, cuando no en un show en sí mismo. De hecho,
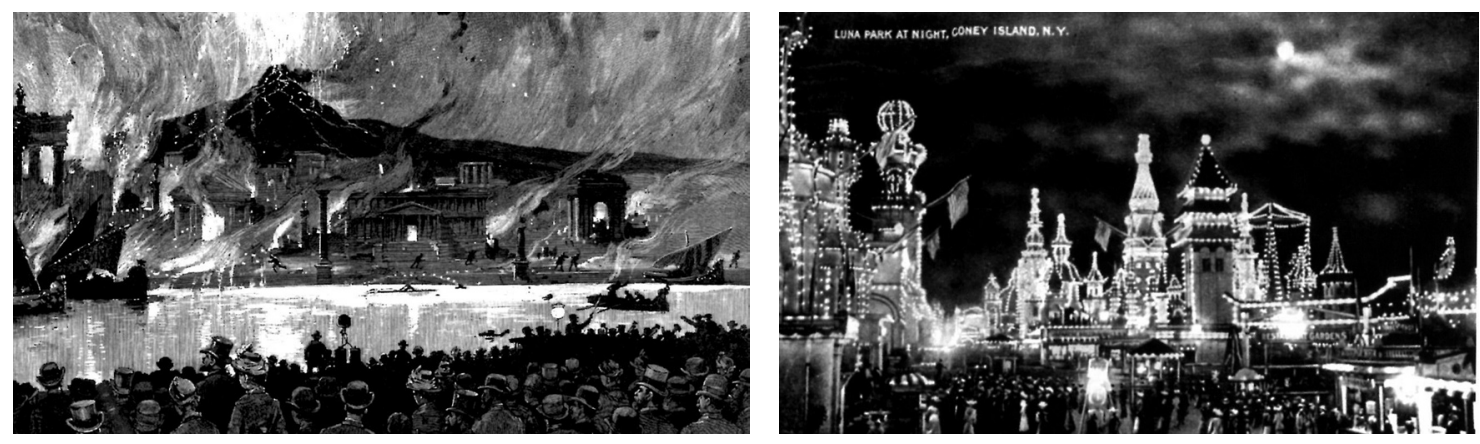
como señala Rem Koolhaas, esa especie de exótico y kitsch "Bagdad de las Mil y una noches" redivivo, que formaban las torres incontables de las atracciones de Luna Park iluminadas de noche por colores innúmeros, era considerado por uno de sus creadores, el ingeniero Frederic Thomson, como una suerte de manifiesto. "He construido el Luna Park", declaraba Thomson, "a partir de un proyecto arquitectónico bien definido. Como es un lugar de diversión, he eliminado de su estructura todas las formas clásicas convencionales y he adoptado para mi modelo una especie de estilo libre y oriental (...) con el fin de conseguir ese efecto de inquietud y alegría que siempre debe derivar de las gráciles líneas propias de este estilo de arquitectura". Y añadía, henchido de orgullo: "Resulta maravilloso cómo es posible contribuir al despertar de las emociones humanas mediante el uso arquitectónico que se puede hacer de las líneas simples. El Luna Park está construido a partir de esa teoría, y el resultado ha demostrado que esta teoría merece la pena." ${ }^{14}[22]$.

El modelo de Luna Park constituía, de este modo, una alternativa al esquema decantado durante la primera generación de los panoramas -afín a su vez a la relación interior/exterior del teatro de Bayreuth-, en el que la intensidad estilística se centraba en la configuración del espacio interno -es decir, allí donde se producía la atmósfera-, mientras que el aspecto del edificio hacia la calle era, sin más, la expresión, a menudo camuflada mediante publicidad o vuelta presentable con alguna anacrónica columnata, de la geometría pura y generalmente cilíndrica y cupulada de los artefactos panópticos. En el modelo norteamericano, por el contrario, el aspecto de las atracciones se juzgaba relevante, tenía valor en sí mismo, pues daba cuenta del carácter festivo del programa ambiental interno, generando en paralelo un nuevo ludotopo ambiental: el que se derramaba por las calles de la feria. La atmosferología se fusionaba así con la iconografía de acuerdo a una pauta que habría de repetirse más tarde en los parques de atracciones o en ciudades ludotópicas como Las Vegas ${ }^{15}$.

La relación entre la forma y la atmósfera no tenía, por tanto, que traducirse necesariamente en un esquematismo; podía transmutarse con el fin de convertir la piel de los edificios en verdaderas máquinas atmosféricas, al igual que lo eran sus interiores sinestésicos. Con todo, a lo largo del siglo xx, la evolución de los "ludotopos" para las masas acabaría, en su mayor parte, siguiendo otros caminos: por un lado, el del esquematismo formal, cuyo propósito sería jerarquizar la experiencia sinestésica, cediéndole todo el protagonismo a la experimentación del ambiente interior; por el otro, el de volver complementario el adentro y el afuera del edificio, su forma y su atmósfera, mediante estrategias que, en buena medida, habian sido anticipadas en el Crystal Palace. El primero sería adoptado por buena parte de los pabellones efímeros de la segunda mitad del siglo xx; el segundo, por los grandes contenedores que surgirian también por esas fechas.

En realidad, lo que Crystal Palace había resuelto de un modo tan pragmático como estilísticamente incoherente fue el problema de compatibilizar la iconografía exterior de un edificio permanente con un contenido variable a lo largo del tiempo. La tensión pudo diluirse gracias al ca-
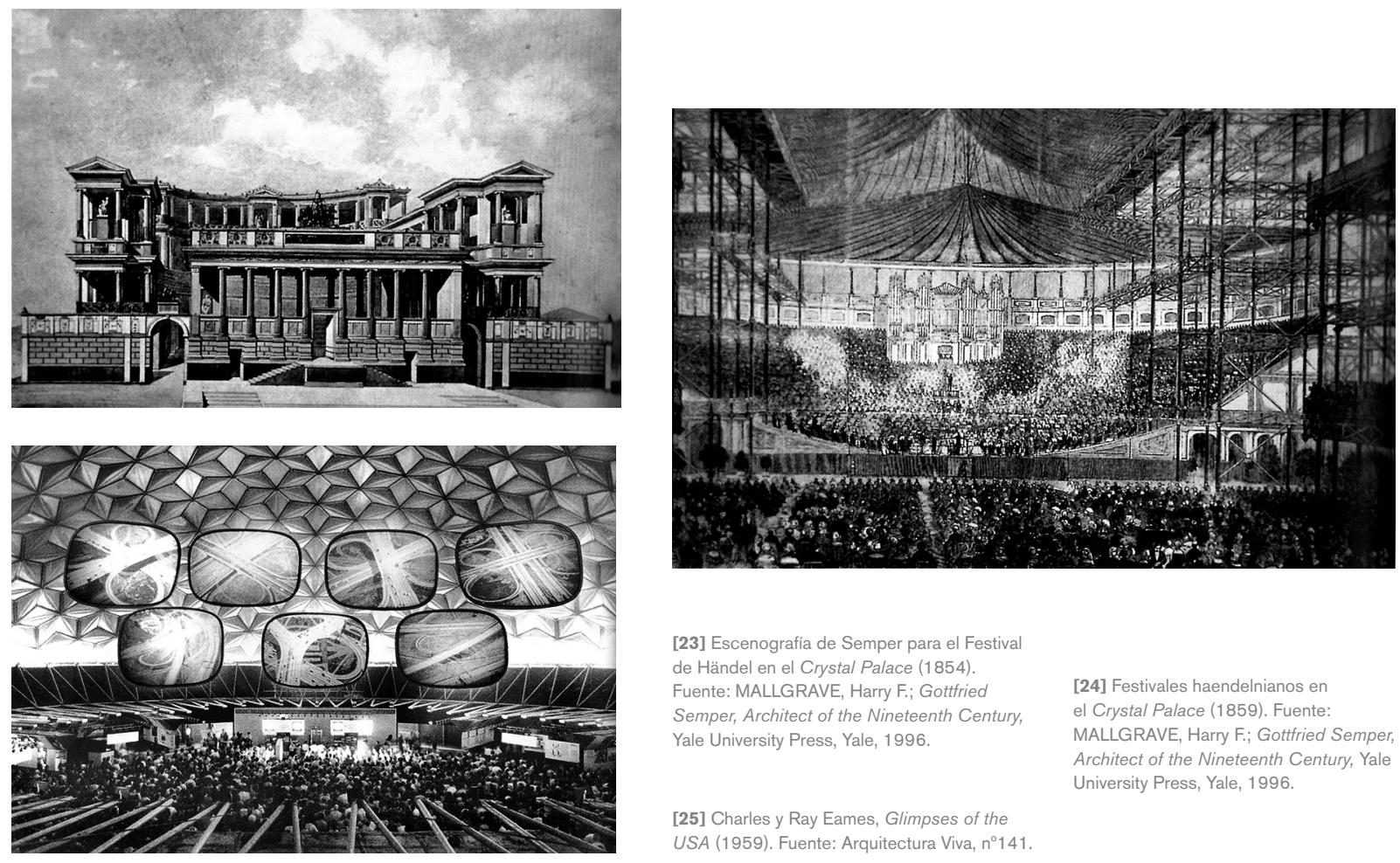

[23] Escenografía de Semper para el Festival de Händel en el Crystal Palace (1854). Fuente: MALLGRAVE, Harry F.; Gottfried Semper, Architect of the Nineteenth Century, Yale University Press, Yale, 1996.

[25] Charles y Ray Eames, Glimpses of the USA (1959). Fuente: Arquitectura Viva, $n^{\circ} 141$
[24] Festivales haendelnianos en el Crystal Palace (1859). Fuente: MALLGRAVE, Harry F.; Gottfried Semper, Architect of the Nineteenth Century, Yale University Press, Yale, 1996. 
14 Ibídem, pp. 39-40.

${ }^{15}$ Véase al respecto MARCHÁN FIZ, Simón; RODRIGUEZ LLERA, Ramón; Las Vegas: resplandor pop y simulaciones posmodernas, 1905-2005, Akal, Madrid, 2005.

16 Véase al respecto PRIETO, Eduardo; "Máquinas o atmósferas. La estética de la energía en la arquitectura, 1750-2000", Directores: Luis Fernández Galiano, Simón Marchan Fiz, [Tesis doctoral] Universidad Politécnica de Madrid, Madrid, 2012, pp. 462-476.

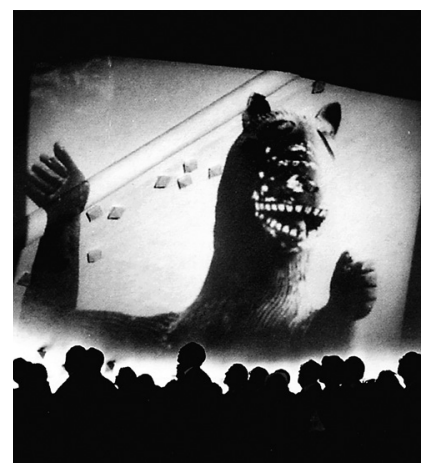

[26] Escena de la proyección electroacústica de Le Corbusier en el Pabellón Philips (1958) Fuente: (Quesada 2004). rácter neutro de la estructura modular y, casi imperceptible, así como de la atmósfera producida dentro del "invernadero": un ambiente homogéneo susceptible de albergar programas diferentes, desde los pabellones históricos hasta las ferias de muestras industriales, pasando incluso por auditorios para representaciones musicales, en particular, los entonces célebres festivales de Händel, que necesitaban gradas para un público inmenso y espacio para una orquesta de hasta 4.000 músicos. En la "catedral" proyectada por Paxton, la celebración de la industria capitalista y colonial devenía la de una incipiente industria cultural que requería un aparato simbólico e iconográfico adecuado. A este tramoya pertenecería también el teatro que Semper proyectó para los festivales haendelianos londinenses, pero que nunca llegaría a construir y que, concebido como una obra de arte total, ocupaba en su totalidad el inmenso crucero del Crystal Palace con una escenografía romana, cromática y a la vez musical, y susceptible de delimitar una atmósfera específica y jerárquica en el contexto de la malla racional e indeterminada del edificio de Paxton. Se daban pie así a dos niveles de intensidad atmosférica: el producido por la envolvente acristalada, que era permanente, genérico y estaba concebido como una suerte de éter compartido; y el generado por cada uno de los pabellones interiores, que eran efímeros, específicos y reconocibles simbólicamente [23, 24].

Por su parte, la opción contrapuesta a la del Crystal Palace -concentrar el esfuerzo en la creación de una atmósfera interior sinestésica, fácilmente reconocible y segregada completamente del exterior- se materializaría en la nueva hornada de pabellones efímeros fruto del resurgir de las exposiciones universales, cuyas convocatorias se habían interrumpido hacia 1900 para abrir paso a la sucesión de guerras que arrasarían Europa en los siguientes cuarenta años. Por supuesto, cuando tales eventos se retomaron en la década de 1950 la situación de la arquitectura había cambiado. No había ya lugar para el eclecticismo orientalizante de un Luna Park, ni para los no menos exóticos ambientes sinestésicos producidos al calor del decadentismo fin-desiècle y del optimismo tecnológico de la Francia de finales del siglo XIx. Después de la II Guerra Mundial, el optimismo se cifraba en la recuperación económica, y la tecnología más puntera no era ya la de la industria pesada, sino la de la recién alumbrada cibernética y las ya pujantes industrias de la información. Este sería el contexto del que surgirían los pabellones electroacústicos de Le Corbusier, lannis Xenakis o Charles y Ray Eames, y las experiencias de integración ambiental entre las artes propias de Jean Labatut, Charles Moore y, en general, buena parte de las vanguardias de las décadas de 1950 y $1960^{16}$ [25-26]. Charles y Ray Eames diseñarían el que fue uno de los primeros espectáculos electroacústicos, Glimpses of USA, en 1959, y colaborarían más tarde con Ero Saarinen en el Pabellón IBM para la Feria de Nueva York (1964). Le Corbusier pergeñaría junto a lannis Xenakis el extraordinario Pabellón Philips para la Exposición Universal de Bruselas (1958), abriendo una nueva senda de fusión entre las artes que, desde finales de la década de 1960, sería desarrollada por el propio Xenakis en sus polytopes. Por su parte, Jean Labatut -que sorprendió con su gran espectáculo "multimedia" del Lagoon of Nations de la Feria Nuevo York de 1939- seguiría la senda de la vieja tradición litúrgica de los espacios sinestésicos en obras tan señaladas como la Iglesia de los cuatro evangelistas (1951), abriendo nuevos caminos a la fusión de las artes que sintonizaban con las propuestas de integración que, por aquellas mismas fechas, se estaban desarrollando en la nueva arquitectura religiosa de toda Europa. Finalmente, la obra litúrgica de Labatut habría de influir en la generación de arquitectos norteamericanos formados en la década de 1960, aquellos que como Charles Moore rechazarían los dogmas de la modernidad canónica para postular una arquitectura fenomenológica, orientada a la construcción de atmósferas a veces hechas al dictado del LSD.

Con todos ellos nacía una nueva generación de arquitecturas lúdicas, atmosféricas y ajenas en buena medida al racionalismo más romo sostenido por entonces como un dogma de fe; edificios y ambientes en los que la sinestesia parecía recuperar su condición, un tiempo perdida, de categoría estética moderna. 